\title{
Abnormal Carbenes as Ligands in Transition Metal Chemistry: Curiosities with Exciting Perspectives
}

\author{
Martin Albrecht*
}

\begin{abstract}
This review compiles the advances achieved in our laboratories using abnormal and less heteroatomstabilized carbenes as ligands for transition metal chemistry. Fundamental studies allowed the evaluation of the impact of this new class of ligands both electronically and sterically. Based on these results, initial catalytic applications have been devised in the area of $\mathrm{H}-\mathrm{H}$ and $\mathrm{C}-\mathrm{H}$ bond activation, demonstrating the potential of abnormal carbenes as unique ligands for transition metals.
\end{abstract}

Keywords: Abnormal coordination mode $\cdot$ Catalytic applications $\cdot N$-Heterocyclic carbenes . Late transition metals $\cdot$ Metal nucleophilicity

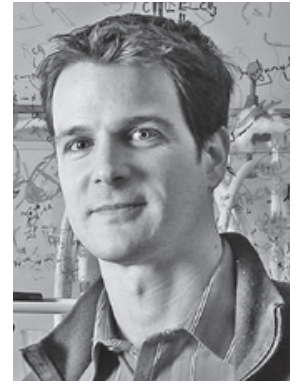

Martin Albrecht studied chemistry at the University of Bern and received his $\mathrm{PhD}$ under the supervision of $\mathrm{Ge}$ rard van Koten from Utrecht University (The Netherlands). After postdoctoral work with Robert $\mathrm{H}$ Crabtree (Yale) and with Ciba SC (Basel), he was awarded an Alfred Werner Assistant Professorship, which allowed him to initiate his independent research program at the University of Fribourg. His current interests are in (bio)organometallic chemistry in general, with special emphasis on developing novel carbene ligands for catalytic and electronic applications. He has recently received a Starting Grant from the European Research Council to explore new twists in this area.

\footnotetext{
${ }^{*}$ Correspondence: Prof. Dr. M. Albrecht Department of Chemistry

University of Fribourg

Chemin du Musée 9

$\mathrm{CH}-1700$ Fribourg

Tel. : +41263008786

Fax: + 41263009738

E-mail: martin.albrecht@unifr.ch
}

\section{Introduction}

The discovery of $N$-heterocyclic carbenes (NHCs) as versatile ligands for transition metals constitutes one of the most influential developments in organometallic chemistry of the last decade. ${ }^{[1]}$ Research has been stimulated in a number of areas in materials science and remarkable advances have been made in fabricating new components for light-emitting diodes ${ }^{[2]}$ and electronic devices. ${ }^{[3]}$ By far the most impressive results have been obtained undoubtedly in the development of new catalytic systems. ${ }^{[4]}$ Some metal NHC complexes are extremely powerful catalysts, perhaps most evidently illustrated by Grubbs' second-generation olefin metathesis catalyst, ${ }^{[5]}$ or by the palladium NHC complexes introduced by Organ and currently commercialized by Aldrich as cross-coupling catalysts. ${ }^{[6]}$ The catalytic activity of these complexes is extraordinarily high, often surpassing the ubiquitous phosphine analogs in homogeneous transformations. The outstanding performance of NHC complexes has been generally attributed to the strong $\mathrm{M}-\mathrm{C}_{\mathrm{NHC}}$ bond and to the high donor ability of carbene ligands. Notably, electron donation of the carbene ligand may be further enhanced upon displacing or removing one or both heteroatoms adjacent to the carbene. From a historical perspective, such heteroatom engineering has been less considered, as the popularity of NHCs has relied by and large on the stability of the free carbene. ${ }^{[7]}$ The availability of free carbenes has opened a straightforward access to transition-metal chemistry, as ligand coordination with carbenes is comparable to the bonding of other neutral donor ligands to a metal center, with the exception that in carbene chemistry metal-ligand bonds are kinetically essentially inert.

The limitations in carbene chemistry in terms of presence and location of heteroatoms has lately been overcome independently by two different approaches. Predominantly through the pioneering work of Bertrand and coworkers, a variety of free carbenes with reduced heteroatom stabilization have been shown to be stable.[8] Crystal structures and coordination properties have been disclosed for cyclic and acyclic carbenes with only one heteroatom adjacent to the carbene, or none at all as in cyclopropylidene or a recently reported allene. ${ }^{[9]}$ In parallel to these achievements, new methodologies for the metallation of imidazolium salts have been developed that avoid the formation of free carbenes. Protocols include in particular direct metallation via $\mathrm{C}-\mathrm{H}$ bond activation, transmetallation, oxidative $\mathrm{C}-\mathrm{X}$ and $\mathrm{C}-\mathrm{H}$ addition, and formation of the carbene at the metal by alkylation of the corresponding anionic azolyl ligand. ${ }^{[10]}$ As a direct consequence of these developments, the stability of the free carbene is now only of minor relevance to the formation of metal NHC complexes.

Rather serendipitously, efforts in these directions uncovered that metallation may occur at positions different from the expected one (Scheme 1). ${ }^{[11]}$ In imidazolium salts, the $\mathrm{C}(2)$-bound proton has by far the largest acidity ${ }^{[12]}$ and is therefore generally considered to be easiest to activate. ${ }^{[13]}$ However, with iridium precursors, evidence has been provided that in some cases, the $\mathrm{C}(4)$ position may be more susceptible to metallation than the $\mathrm{C}(2)$ position, hence leading to abnormal carbene bonding. ${ }^{[14]}$ While the terms 'normal' and 'abnormal' have initially been used to differentiate between the 


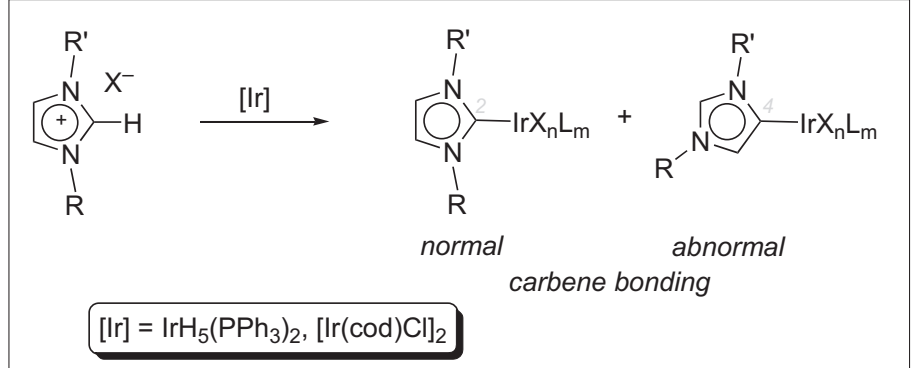

Scheme 1.

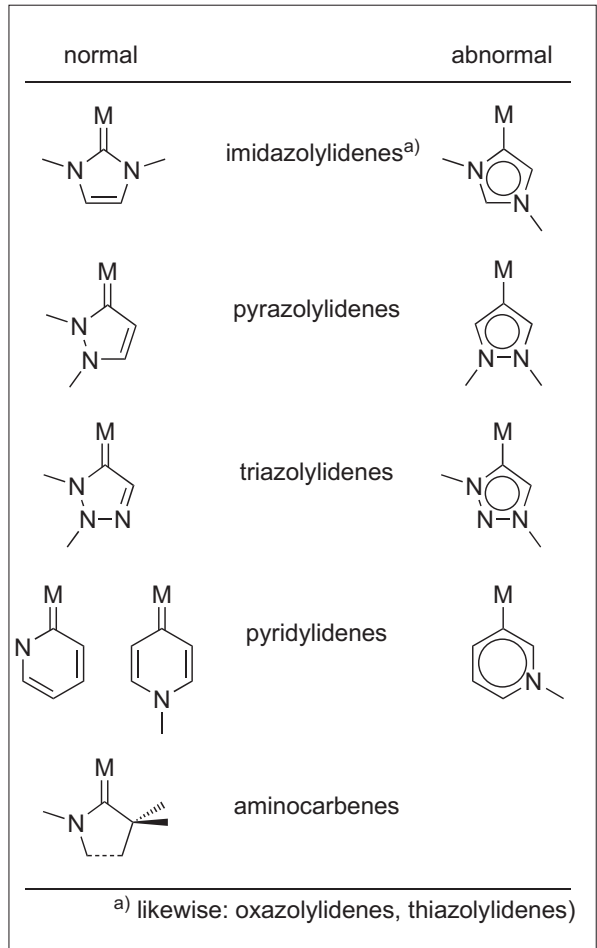

Fig. 1. Selection of abnormal and normal heterocyclic carbene ligands bound to a metal center. For the sake of clarity, the normal carbene complexes are represented by $\mathrm{M}=\mathrm{C}$ double bonds, though the bonding differences between normal and abnormal carbenes to metals is assumed to be less pronounced than the drawing here may imply.

supposedly more stabilized (normal) C(2) and the $\mathrm{C}(4)$ position, this terminology has recently been expanded to the general area of NHC chemistry. ${ }^{[15]}$ Thus, a normal carbene refers to a carbene, for which a neutral canonical resonance form can be drawn, while an abnormal carbene requires the introduction of either charges or diradicals in the carbene-type resonance form (Scheme 2). With this broader definition, a range of abnormal carbene ligands are conceivable (Fig. 1), ${ }^{[15]}$ and many of these have been studied as ligands for transition metals, yet only in one case, a free abnormal carbene has been isolated and characterized by $\mathrm{X}$ ray diffraction. ${ }^{[9]}$

Our own interest in using such abnormal carbenes as ligands for catalytically

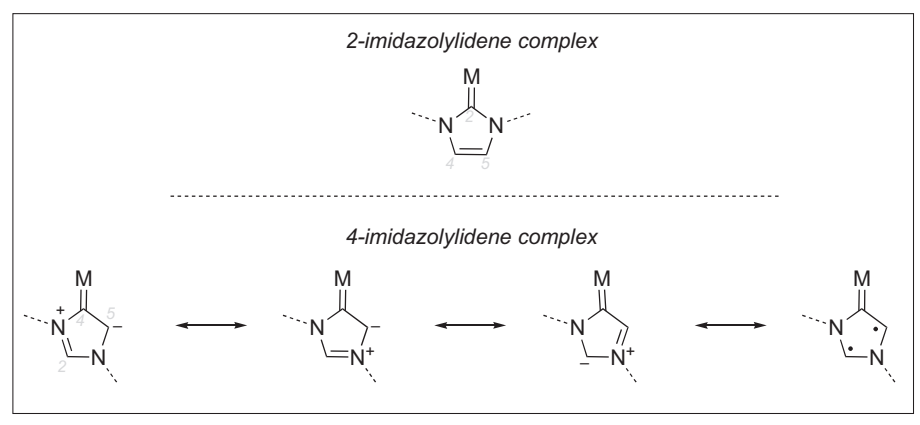

Scheme 2.

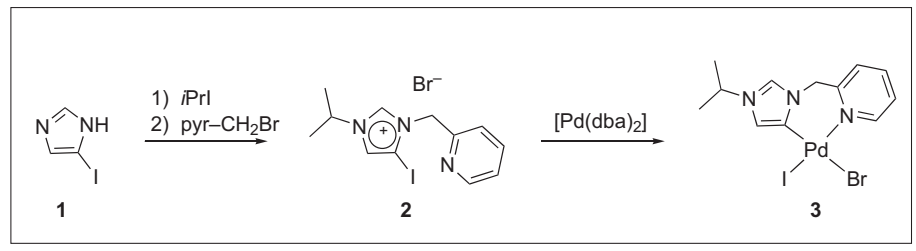

Scheme 3.

active metal centers has been stimulated predominantly by the fact that these ligands should be extraordinarily strong donors, significantly stronger than their normal analogs, which are considered as being amongst the strongest donor ligands known to date. Exceptional donor properties are surmised since the inductive electronwithdrawing effects of the heteroatoms are less prevalent if only one heteroatom is placed adjacent to the carbene. This report summarizes our advances in this area and includes first catalytic applications arising from the unique bonding properties of abnormal carbene ligands.

\section{Abnormal Imidazolylidene Complexes}

In order to direct metallation to the $\mathrm{C}(4)$ position of imidazolium salts, ${ }^{[16]}$ two general strategies appear to be particularly useful:[17] i) activation of the $\mathrm{C}(4)$ position, and ii) deactivation of the generally more reactive $\mathrm{C}(2)$ position.

\subsection{Metallation via Activation of the Imidazolium C(4) Position}

Incorporation of a halide at the imidazole $\mathrm{C}(4)$ position and subsequent alkylation and quaternization of the nitrogen centers provides imidazolium salts for oxidative addition to a low valent metal center. We have demonstrated the feasibility of this approach by starting from 4-iodoimidazole 1, which has been regioselectively $\mathrm{N}$-alkylated and subsequently quaternized with a chelating donor group. Oxidative addition to palladium( 0 ) affords complex 3 comprising a chelating C(4)-bound imidazolylidene ligand (Scheme 3). ${ }^{[18]}$ Variable temperature analysis has shown that the abnormal bonding mode is thermally stable at least up to $100{ }^{\circ} \mathrm{C}$. No rearrangement to the presumably thermodynamically more stable $\mathrm{C}(2)$-bound isomer has been detected. Current investigations in our laboratories indicate that this halogenation/oxidative addition methodology can be expanded to the synthesis of a variety of different abnormal carbene complexes, [19] thus providing a general access to this class of ligands.

\subsection{Metallation via Deactivation of the Imidazolium C(2) Position}

Protection of the imidazolium C(2) position provides an alternative methodology to the activation protocol in order to direct metallation to the imidazolium $\mathrm{C}(4)$ position. Efficient blocking of the $\mathrm{C}(2)$ carbon has been accomplished by introducing an alkyl or an aryl group. A number of 2-alkylated and 2-arylated imidazoles are commercially available or readily accessible by simple synthetic protocols, thus providing a straightforward feedstock for this type of ligand precursors. Substitution effectively blocks the $\mathrm{C}(2)$ position and generally directs metallation to the $\mathrm{C}(4)$ position. Notably, alkylation of the $\mathrm{C}(2)$ position is not always reliable and under certain conditions, activation of an exocyclic $\mathrm{C}\left(\mathrm{sp}^{3}\right)-\mathrm{H}$ bond may be competitive with $\mathrm{C}(4)-\mathrm{H}$ bond activation. Such reactions have been observed with strong bases, including $\mathrm{Ag}_{2} \mathrm{O}$ and with iridium precursors, and may yield the corresponding exocyclic olefin, a metal-alkyl complex, or even lead to $\mathrm{C}-\mathrm{C}$ bond breaking and normal imidazolylidene coordination. ${ }^{[20]}$

Such undesired reaction trajectories are suppressed, either by protecting the $\mathrm{C}(2)$ position with an aryl group, i.e. with a group lacking $\alpha$ hydrogens, or by direct $\mathrm{C}-\mathrm{H}$ bond activation using a mildly basic 
metal precursor. This approach has been utilized to prepare different complexes containing $\mathrm{C}(4)$-bound imidazolylidene ligands. ${ }^{[21]}$ We have extended the methodology to cis-coordinating dicarbene systems. In such chelating ligands, the rotational flexibility of the carbene ligand is restricted, which is expected to result in a reduced lability of the complex towards reductive elimination. In addition, in squareplanar $\mathrm{d}^{8}$ metal complexes, the remaining two positions are labilized as they are both trans to a carbene ligand. Therefore, the anticipated high trans influence and trans effect of abnormal carbenes can be ideally exploited. In addition, the corresponding normal dicarbene complexes are known ${ }^{[22]}$ and allow for comparative studies.

For example, palladation of the $\mathrm{C}(2)$ protected diimidazolium salts $\mathbf{4}$ with $\mathrm{Pd}(\mathrm{OAc})_{2}$ affords complexes 5 comprising C(4)-bound diimidazolylidene ligands (Scheme 4). ${ }^{[23]}$ The conditions applied for this metallation are virtually identical to those used for the preparation of the normal analog, which may suggest that $\mathrm{C}-\mathrm{H}$ bond activation is probably not rate-limiting. Based on metallation studies including the palladation of a dissymmetric potentially normal-abnormal diimidazolium salt, a rationale for the selective activation of the $\mathrm{C}(4)-\mathrm{H}$ bond in the diimidazolium precursor salts has been proposed. ${ }^{[24]}$ Thus, formation of a palladate $\left[\mathrm{PdX}(\mathrm{OAc})_{2}\right]^{2-}$ seems to be fast and essential for the subsequent steps. In studies using imidazolium salts with noncoordinating counterions such as $\mathrm{BF}_{4}^{-}$or $\mathrm{PF}_{6}^{-}$, metallation is suppressed. The palladate is supposed to be stabilized by the dicationic imidazolium salt in what may be best described as an ion pair (A, Scheme 4). In addition to the electrostatic interactions, further stabilization may arise from hydrogen bonding of the acetate oxygen with the most acidic hydrogen of the imidazolium salt, viz. $\mathrm{C}(2)-\mathrm{H}$ in normal and $\mathrm{C}(4)-\mathrm{H}$ in $\mathrm{C}(2)$-protected imidazolium cations. Such a hydrogen bond interaction weakens the $\mathrm{C}-\mathrm{H}$ bond and at the same time, increases the nucleophilicity of the carbon, which is assumed to be a critical factor for promoting C...Pd interactions. Moreover, such a model rationalizes the selectivity observed for $\mathrm{C}(4)-\mathrm{H}$ rather than $\mathrm{C}(5)-\mathrm{H}$ bond activation in the imidazolium salt 4 . In an idealized case, the $\mathrm{H}_{\text {imi }} \cdots \mathrm{O}_{\text {acetate }}$ and the $\mathrm{C} \cdot . \mathrm{Pd}$ interactions are established in a concerted process, leading to a six-membered transition state B. Subsequent loss of HOAc from such a transition state is easily conceivable and gives C. Interestingly, complexes related to $\mathbf{C}$ are resistant towards acidolysis (e.g. using HOAc), indicating that the A-to- $\mathbf{C}$ transformation is an irreversible process and hence not thermodynamically controlled.

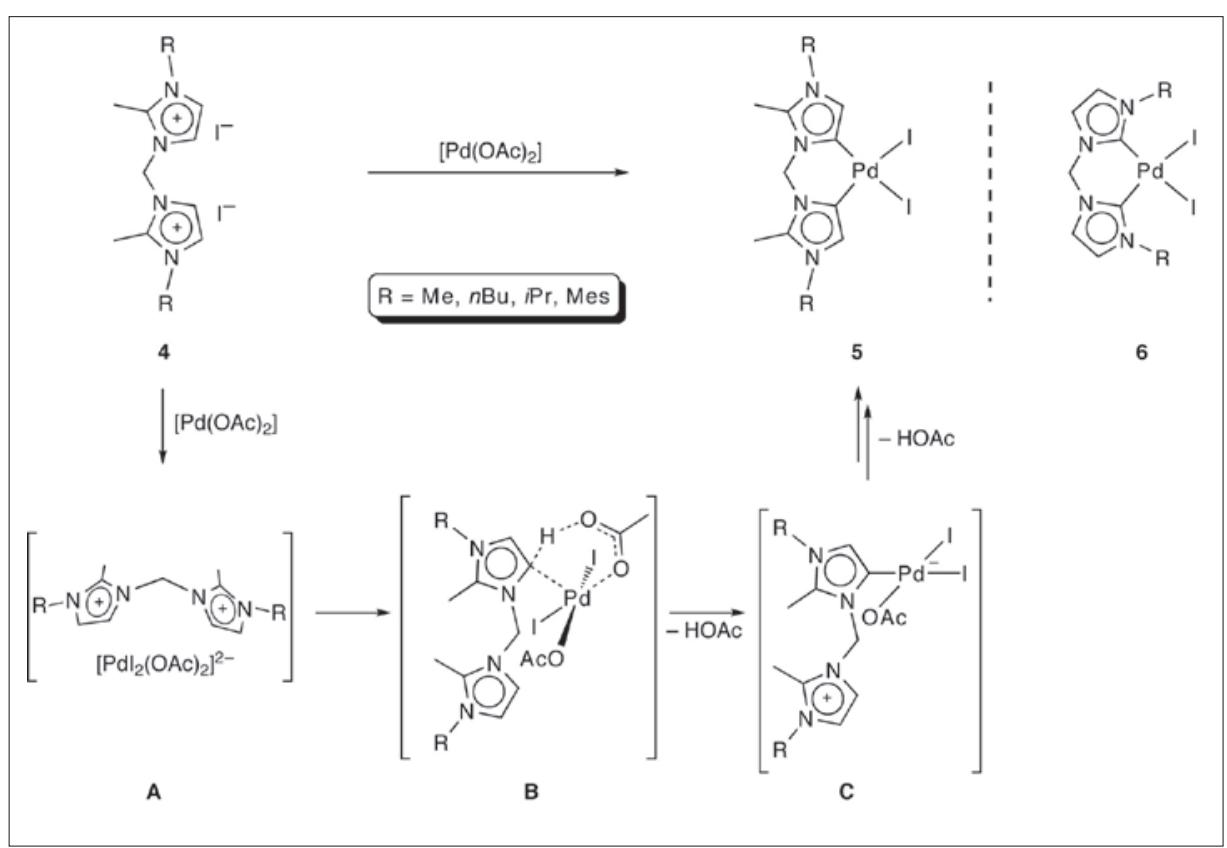

Scheme 4.

Formation of the second $\mathrm{C}-\mathrm{Pd}$ bond from the monocarbene complex $\mathbf{C}$ may occur according to a similar mechanism, though the palladate in $\mathbf{C}$ is less anionic than in $\mathbf{A}$ due to the substitution of an acetate ligand by a heterocyclic carbene. As a consequence, the $\mathrm{H}_{\text {imi }} \ldots \mathrm{O}_{\text {acetate }}$ interaction may be less pronounced. In normal carbenes, this reduced activity may be compensated by the relatively high acidity of the $\mathrm{C}(2)$-bound proton, while for abnormal carbenes, the increased donor properties of the ligand may weigh out the lower C(4)$\mathrm{H}$ acidity. This situation becomes delicate in the mixed normal-abnormal carbene precursor 7 (Scheme 5), in which the intermediate monocarbene complex experiences low palladate character due to the normal bonding of the carbene paired with the low acidity of the $\mathrm{C}(4)$-bound proton. Based on the model sketched above, it is not surprising that this intermediate fails to cyclometallate and arrests at the monocarbene stage. After anion metathesis, complex 8 has been isolated in good yields.

The reactivity of the dicarbene complexes $\mathbf{5}$ and $\mathbf{6}$ towards Lewis acids such as $\mathrm{Ag}^{+}$ions and towards Brønsted acids $\left(\mathrm{H}_{2} \mathrm{SO}_{4}, \mathrm{H}_{3} \mathrm{PO}_{4}, \mathrm{HOAc}\right)$ has revealed that abnormal $\mathrm{C}(4)$ bonding of the carbenes markedly increases the nucleophilicity of the coordinated metal center as compared to $\mathrm{C}(2)$ bonding. Despite its formal +2 charge, the palladium center in these complexes is best described as a Lewis base. The abnormal carbene bonding mode induces new reaction patterns such as the formation of a stable and crystallographically characterized $\mathrm{Pd}-\mathrm{Ag}$ adduct. [23,25]

Some of the reactivity differences of normal and abnormal imidazolylidene complexes may, in principle, be a consequence of steric differences. In particular the absence of a wingtip group in ortho position to the carbene alters the accessibility of the coordinated metal center and may render the $\mathrm{M}-\mathrm{C}_{\mathrm{NHC}}$ bond more susceptible. In addition, in normal carbenes, the steric demand of the wingtip groups forces the carbene ligand to bend out of the coordination plane (dihedral angles between palladium square plane and heterocycles are typically around $40^{\circ}$ ), while in abnormal imidazolylidenes containing a hydrogen at the $\mathrm{C}(5)$ nucleus, the twist tends to be much smaller (dihedral angles around $28^{\circ}$ ). These geometrical differences influence the orbital orientation and may hence

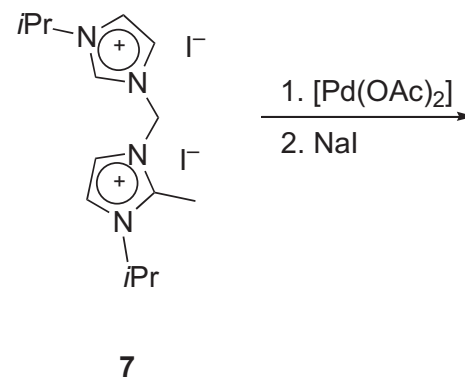

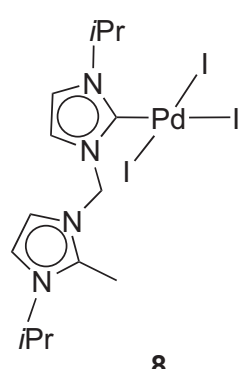

8 


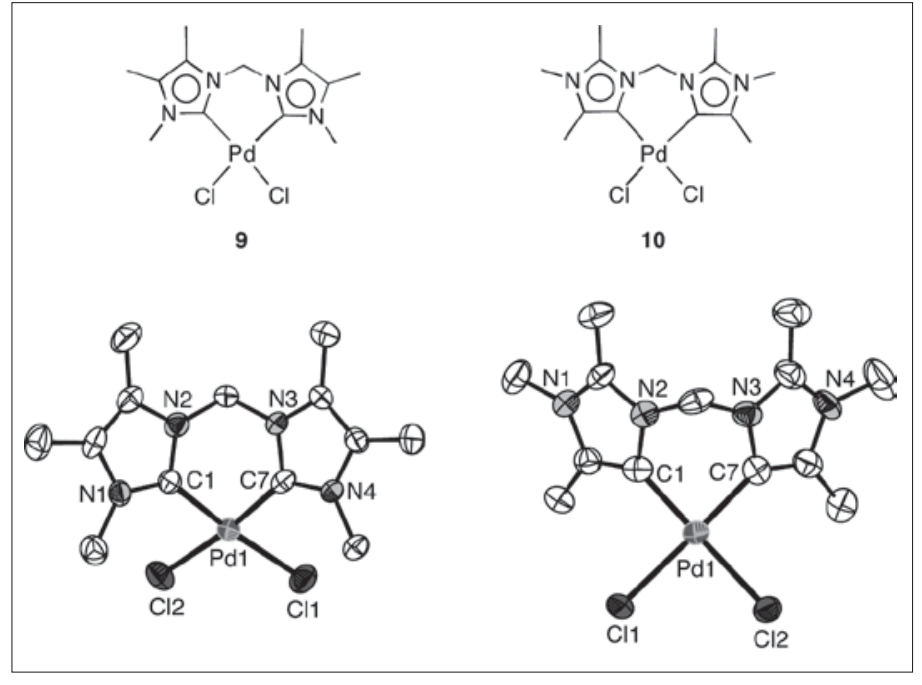

Fig. 2. Schematic representation of the isostructural complexes $\mathbf{9}$ and $\mathbf{1 0}$ including their crystal structures (ORTEPs at $50 \%$ probability level).

be a potential source for distinct stereoelectronic effects.

In order to unambiguously evaluate the electronic impact of C(4) bonding in imidazolylidene ligands, we have synthesized the palladium complexes $\mathbf{9}$ and $\mathbf{1 0}$ (Fig. 2 ). These complexes comprise sterically identical permethylated dicarbene ligands which bind the metal center in a normal coordination mode via $\mathrm{C}(2)$ and abnormally via $\mathrm{C}(4)$, respectively. ${ }^{[25]}$ Due to the strong structural analogy of the complexes, differences in reactivity patterns may be attributed to the electronic impact of normal $v s$ abnormal carbene bonding exclusively, while stereoelectronic effects are negligible.

The most substantial structural differences between complexes $\mathbf{9}$ and $\mathbf{1 0}$ are found in the metal-halide bond lengths. The $\mathrm{Pd}-\mathrm{Cl}$ bonds are considerably longer in the abnormal carbene complex $\mathbf{1 0}$ than in $\mathbf{9}$

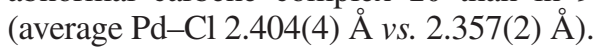
This difference illustrates the larger trans influence of C(4)-bound carbenes.

Unique reactivity patterns have been identified for the abnormal carbene complexes, specifically upon reaction with Lewis acids and in oxidative addition-reductive elimination sequences. In line with previous studies on the reductive elimination from palladium(II) complexes of abnormal carbenes, ${ }^{[26]}$ reductive elimination of the carbene ligand is strongly promoted also from palladium(Iv) centers. Depending on the substitution pattern on the $\mathrm{C}(5)$ position, either reductive $\mathrm{C}_{\mathrm{NHC}}-\mathrm{C}_{\mathrm{NHC}}$ elimination (for $\mathrm{H}$ attached to $\mathrm{C}(5)$ ) or reductive carbon-halogen elimination (for $\mathrm{CH}_{3}$ attached to $\mathrm{C}(5)$ ) has been observed. In contrast, the $\mathrm{C}(2)$-bound dicarbene complexes are resistant towards such reductive elimination patterns. These reactivities as well as analytical investigations using $\mathrm{X}$ ray diffraction and $\mathrm{X}$-ray photoelectron spectroscopy indicate that the $\mathrm{C}(4)$ bonding mode increases the electron density at the metal center substantially, placing such C(4)-bound carbene ligands amongst the most basic neutral donors known thus far. ${ }^{[27]}$ A direct application of this enhanced electron density at the metal center is demonstrated by the catalytic $\mathrm{H}_{2}$ activation with abnormal carbene complexes under mild conditions, leading to a catalytic process for the hydrogenation of olefins. Notably, the normal dicarbene analogs display only very low hydrogenation activity.

Direct metallation of the $\mathrm{C}(2)$ protected diimidozolium salts 4 with $\mathrm{RhCl}_{3}$ or $[\mathrm{RhCl}(\operatorname{cod})]_{2}$ and $\mathrm{KI}$ affords the rhodium(III) complexes 11 comprising abnormally $\mathrm{C}(4)$-bound cis-chelating dicarbene ligands (Scheme 6). ${ }^{[28]}$ Similar to the palladation reaction, the presence of acetate ions is pivotal for successful metallation with rhodium. Moreover, detailed analyses of the metallation using $[\mathrm{RhCl}(\mathrm{cod})]_{2}$ suggest that prior to metallation, the rhodium(I) precursor is oxidized in a cascade transformation involving air and the iodide/iodine couple to rhodium(III). Accordingly, metallation takes place with the more electrophilic rhodium(III) nucleus rather than with rhodium(I). These observations are consistent with the mechanism depicted above and do not support an oxidative $\mathrm{C}_{\mathrm{imi}}-\mathrm{H}$ bond activation process.
Scheme 6.
The complexes have been isolated as dimetallic species containing two $\left(\mu^{2}-\mathrm{I}\right)_{3}$ bridged rhodium(III) centers. In the presence of coordinating solvents (e.g. $\left.\mathrm{CH}_{3} \mathrm{CN}\right)$ or exogenous ligands such as $\mathrm{PPh}_{3}$, the dimeric structure is cleaved to yield the monometallic complexes 12. Crystallographic analyses indicate a considerably higher trans influence of abnormal C(4)bound carbenes as compared to normally coordinating imidazolylidenes. The unique bonding properties have been exploited for developing an efficient catalytic process for the transfer hydrogenation of ketones using $i \mathrm{PrOH}$ as dihydrogen source. While typically, rhodium(I) precursors are used for such reactions, the exceptionally strong donor ability of 4-imidazolylidenes allows for using less oxidation-sensitive rhodium(III) catalysts. When ligated by weaker donating $\mathrm{C}(2)$-bound dicarbenes, the rhodium center shows negligible activity in hydrogen transfer catalysis.

Further studies indicate that $\mathrm{C}-\mathrm{H}$ bond activation is not restricted to the highly activated carbinol $\mathrm{C}-\mathrm{H}$ bond in $i \mathrm{PrOH}$, as required for transfer hydrogenation. As a consequence of the high nucleophilicity of the rhodium center due to abnormal imidazolylidene bonding, cleavage of an unactivated $\mathrm{C}_{\text {alkyl }}-\mathrm{H}$ bond has recently been observed. ${ }^{[29]}$ These preliminary results may underpin the great potential of abnormal carbenes in mediating bond activation processes under remarkably mild conditions.

\subsection{Bonding Considerations}

The extraordinary high donor strength of C(4)-bound imidazolylidenes points to an increased relevance of a zwitterionic resonance form as opposed to a carbene-type resonance structure ( $c f$. Scheme 2). A zwitterionic form may be energetically more favored in $\mathrm{C}(4)$-bound carbenes as compared to $C(2)$-bound analogs, since the negative and positive formal charges are better separated and do not both reside on the $\mathrm{NCN}$ fragment. According to this model, a C(4)bound imidazolylidene may be divided in a first approximation into an anionic vinyl $\mathrm{C}=$ $\mathrm{C}$ residue and an $\mathrm{NCN}$ amidinium cation as intramolecularly appended charge compen-

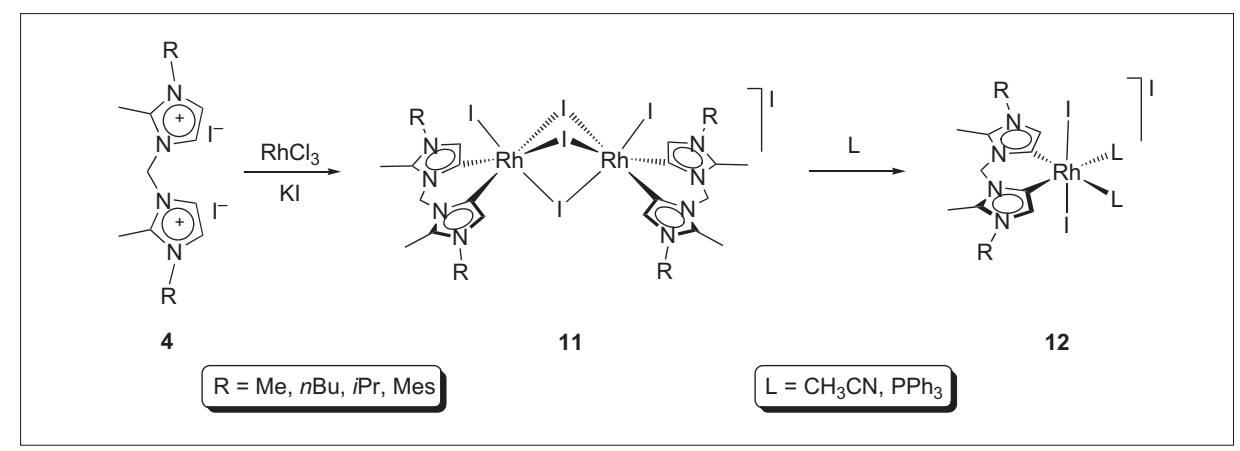




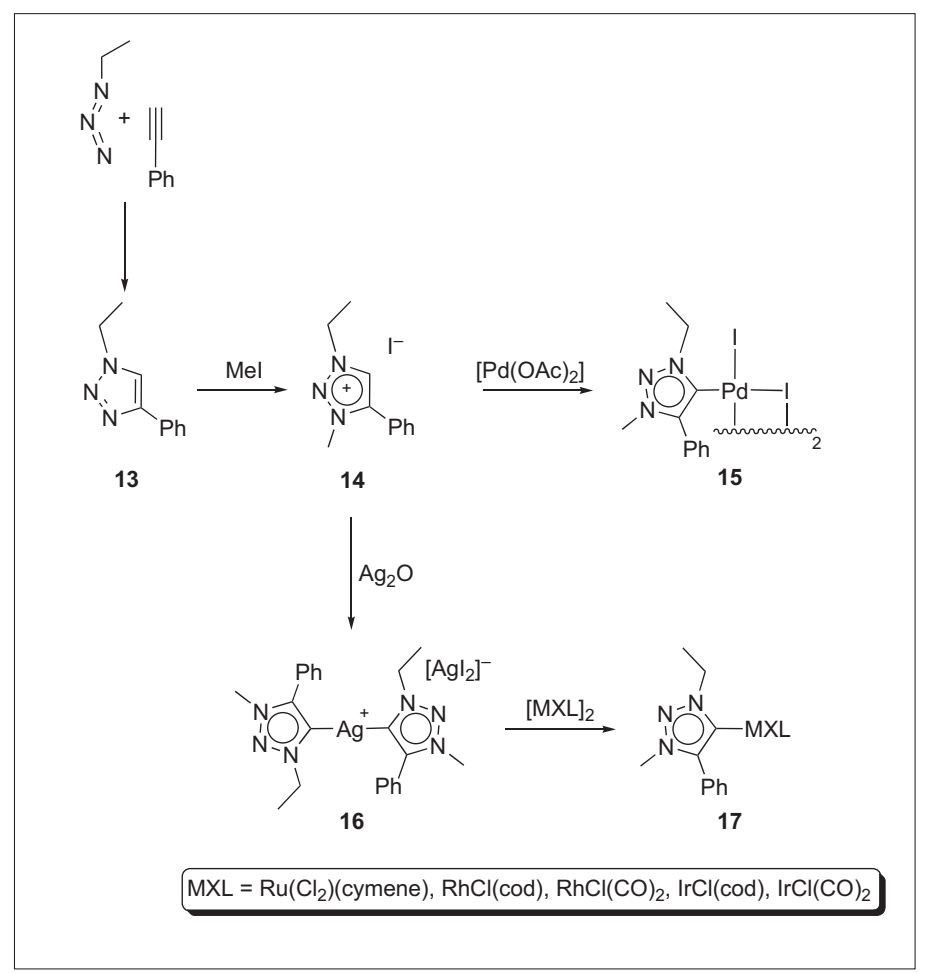

Scheme 7.

sation. Combined with the reduced inductive effects of the heteroatoms noted previously, such vinyl-type, formally anionic ligand bonding may rationalize the higher donor power of C(4)-bound imidazolylidenes as compared to their $\mathrm{C}(2)$-bound homologs. While this model casts some doubt on the use of the term 'carbene', similar considerations apply for carbenes derived from related azolium precursors such as triazolylidenes and pyridylidenes, but also for most of the Fischer-type carbene ligands. [30] For clarity, convenience, and consistency, however, the term 'carbene' seems most warranted.

\section{Abnormal Triazolylidene Complexes}

Formation of abnormal triazolylidene complexes has recently been accomplished by using 1,2,3-triazoles as precursors for ligand synthesis (Scheme 7). ${ }^{[31]}$ Such triazole heterocycles are accessible via a highly versatile 1,3-dipolar cycloaddition reaction of azides and acetylenes ('click chemistry', Huisgen cycloaddition), allowing for the introduction of a variety of functionalities in the ligand skeleton. Methylation of the 1,4-disubstituted triazole $\mathbf{1 3}$ at the $\mathrm{N}(3)$-position is selective and yields the triazolium salt $\mathbf{1 4}$ as precursor for abnormal carbene bonding (Scheme 7). Metallation of has been successfully performed via $\mathrm{C}-\mathrm{H}$ bond activation using $\left[\mathrm{Pd}(\mathrm{OAc})_{2}\right]$ to give the dimeric complex $\mathbf{1 5}$ along with monometallic complexes. ${ }^{[32]}$

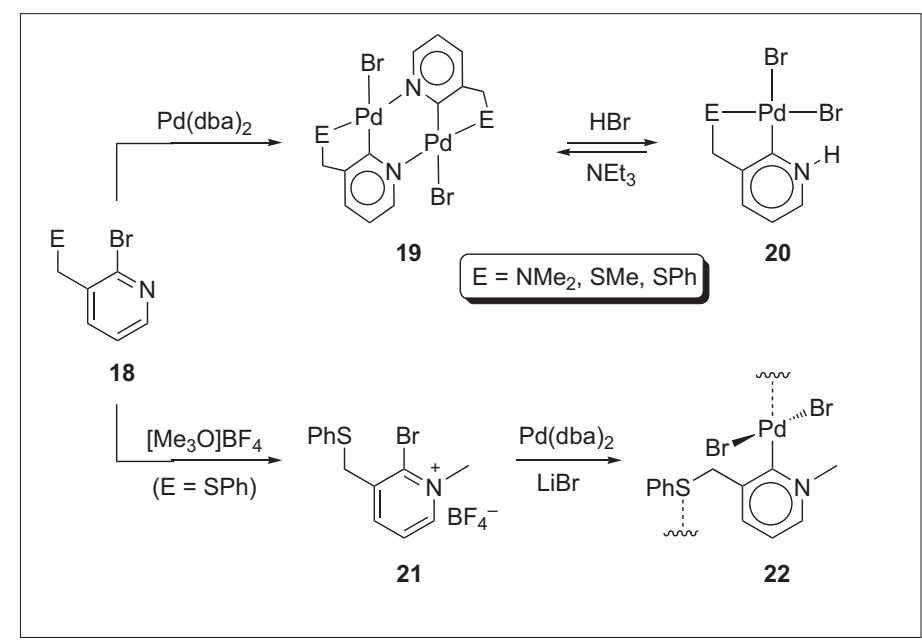

Scheme 8.

of such a putative carbene is high, which renders complex formation via the free carbene route difficult. Hitherto, free pyridylidenes have been characterized only in the gas phase by mass spectrometry. ${ }^{[34]}$

A versatile methodology to install transition metal centers on pyridinium salts comprises oxidative addition. Following pioneering work by Raubenheimer and coworkers, ${ }^{[35]}$ we have introduced potentially chelating donor groups to the pyridine skeleton. ${ }^{[36]}$ The corresponding bromopyridine $\mathbf{1 8}$ may be transformed into a pyridylidene complex either by a classical reaction sequence involving first nitrogen quaternization and then metal insertion, or alternatively via oxidative addition and subsequent nitrogen quaternization (Scheme 8).

Thus, oxidative addition of the 2-bromopyridines 18 to palladium(0) yields the $C, E$-bidentate coordinating pyridyl palladium(II) complexes 19, which exist as dimeric structures due to pyridine nitrogen coordination to another palladium center. Upon protonation, the monometallic 2-pyridylidene complexes $\mathbf{2 0}$ form reversibly. Less reversible alkylation of the pyridine nitrogen appears to be disfavored, presumably due to the ortho shielding effect of the palladium fragment. Quaternization of $\mathbf{1 8}$ before metallation and subsequent oxidative addition of the pyridinium salt 21 to $\mathrm{Pd}(\mathrm{dba})_{2}$ provides access to the pyridylidene complex 22. Notably, $\mathrm{N}$-methylation inhibits a chelating ligand coordination mode, since upon chelate formation, the ligand trans to the SPh donor group would be located in too close proximity to the $\mathrm{N}$-bound $\mathrm{CH}_{3}$ group. Instead, complex 22 exists as a one-dimensional polymer.

The palladium pyridylidene complexes are moderately active catalysts in the Heck-type arylation of styrene. Mechanistic studies support a heterogeneous mode of action, which includes the loss of the pyridylidene ligand from the metal coor- 
dination sphere. Such reaction trajectories may need to be taken into account when refining pyridylidene type complexes for cross-coupling catalysis.

\section{Conclusions}

Advances in transition metal-mediated catalysis show a remarkably good correlation with the discovery and implementation of strong donor ligands. Considerable improvements have been achieved at different stages, for example when introducing aryl phosphines in the late 1950s, upon employing alkyl phosphines in the late 70s, and again with the application of $\mathrm{C}(2)$ bound imidazolylidenes at the end of the last millennium as ligands to the catalytically active metal center. All experimental and theoretical evidence now suggests that abnormal carbenes are even stronger ligands, surpassing the donor properties of the popular, highly heteroatom-stabilized 2-imidazolylidenes substantially. We have started to use these unique ligand properties by developing first catalytic applications where electron-rich metal centers play a key role, such as in $\mathrm{H}-\mathrm{H}$ and $\mathrm{C}-\mathrm{H}$ bond activation. When taking into account the vast possibilities for ligand tuning, abnormal carbenes have great potential for catalytically activating unreactive bonds under mild conditions.

\section{Acknowledgements}

The author is strongly indebted to his current and former coworkers for their enthusiasm and dedication in developing this exciting field of research, and to Antonia Neels and Andreas Ehlers for fruitful collaborations. Our research in carbene chemistry has been financially supported by the Swiss National Science Foundation, ERA-net Chemistry, COST Action D40 and Sasol. M.A. gratefully acknowledges an Assistant Professorship from the Alfred Werner Foundation.

Received: February 2, 2009

[1] a) D. Bourissou, O. Guerret, F. P. Gabbai, G. Bertrand, Chem. Rev. 2000, 100, 39; b) F. E. Hahn, M. C. Jahnke, Angew. Chem., Int. Ed. 2008, 47, 3122.

[2] T. Sajoto, P. I. Djurovich, A. Tamayo, M. Yousufuddin, R. Bau, M. E. Thompson, R. J. Holmes, S. R. Forrest, Inorg. Chem. 2005, 44, 7992.

[3] a) D. M. Khramov, A. J. Boydston, C. W Bielawski, Angew. Chem., Int. Ed. 2006, 45, 6186; b) L. Mercs, A. Neels, M. Albrecht Dalton Trans. 2008, 5570; c) C. Gandolfi, G. Laurenczy, A. Neels, M. Albrecht, unpublished results.

[4] a) W. A. Herrmann, C. Köcher, Angew. Chem., Int. Ed. 2002, 41, 1290; b) 'N-Heterocyclic Carbenes in Synthesis' Ed. S. P. Nolan, WileyVCH, Weinheim, 2006.

[5] T. M. Trnka, R. H. Grubbs, Acc. Chem. Res. 2001, 34, 18.

[6] a) E. A. B. Kantchev, C. J. O’Brien, M. G. Organ, Angew. Chem., Int. Ed. 2007, 46,
2768. b) C. J. O'Brien, E. A. B. Kantchev, C. Valente, N. Hadei, G. A. Chass, A. Lough, A. C. Hopkins, M. G. Organ, Chem. Eur. J. 2006 12, 4743. c) O. Navarro, N. Marion, J. Mei, S. P. Nolan, Chem. Eur. J. 2006, 12, 5142.

[7] A. J. Arduengo, R. L. Harlow, M. Kline, J. Am. Chem. Soc. 1991, 113, 361 .

[8] a) A. Igau, A. Baceiredo, G. Trinquier, G. Bertrand, Angew. Chem., Int. Ed. Engl. 1989, 28, 621 ; b) C. Buron, H. Gornitzka, V. Romanenko, G. Bertrand, Science 2000, 288, 834; c) S. Sole, H. Gornitzka, W. W. Schoeller, D. Bourissou, G. Bertrand, Science 2001, 292, 1901; d) V. Lavallo, J. Mafhouz, Y. Canac, B. Donnadieu, W. W. Schoeller, G. Bertrand, J. Am. Chem. Soc. 2004, 126, 8670; e) V. Lavallo, Y. Canac, C. Präsang, B. Donnadieu, G. Bertrand, Angew. Chem., Int. Ed. 2005, 44, 5705; e) V. Lavallo, Y. Ishida, B. Donnadieu, G. Bertrand, Angew. Chem., Int. Ed. 2006, 45, 6652; f) S. Nkafuji, J. Kobayashi, T. Kawashima, Angew. Chem., Int Ed. 2008, 47, 1141; g) A. Fürstner, M. Alcarazo, K. Radkowski, C. W. Lehmann, Angew. Chem., Int. Ed. 2008, 47, 8302; h) P. R. Schreiner, H. P Reisenauer, F. C. Pickard IV, A. C. Simmonett, W. D. Allen, E. Matyus, A. G. Csaszar, Nature 2008, 453, 906; for a brief review, see: i) M. Albrecht, ChemPhysChem 2008, 9, 1829.

[9] V. Lavallo, C. A. Dyker, B. Donnadieu, G. Bertrand, Angew. Chem. ,Int. Ed. 2008, 47, 5411.

[10] a) D. Bacciu, K. J. Cavell, I. A. Fallis, L.-L. Ooi, Angew. Chem., Int. Ed. 2005, 44, 5282; b) P. L. Arnold, S. Pearson, Coord. Chem. Rev. 2007, $251,596$.

[11] S. Gründemann, A. Kovacevic, M. Albrecht, J. W. Faller, R. H. Crabtree, Chem. Commun. 2001, 2274.

[12] a) R. W. Alder, P. R. Allen, S. J. Williams, $J$ Chem. Soc., Chem. Commun. 1995, 1267; b) Y.-J. Kim, A. Streitwieser, J. Am. Chem. Soc. 2002, 124, 5757; c) T. L. Amyes, S. T. Diver, J. P. Richard, F. M. Rivas, K. Toth, J. Am. Chem. Soc. 2004, 126, 4366; d) A. M. Magill, K. J. Cavell, B. F. Yates, J. Am. Chem. Soc. 2004, 126, 8717; e) A. M. Magill, B. F. Yates, Aust. J. Chem. 2004, 51, 1205.

[13] a) G. Sini, O. Eisenstein, R. H. Crabtree, Inorg. Chem. 2002, 41, 602; b) R. Tonner, G. Heydenrych, G. Frenking, Chem. Asian J. 2007, $2,1555$.

[14] a) S. Gründemann, A. Kovacevic, M. Albrecht, J. W. Faller, R. H. Crabtree, J. Am. Chem. Soc. 2002, 124, 10473; b) L. N. Appelhans, D. Zuccaccia, A. Kovacevic, A. R. Chianese, J R. Miecznikowski, A. Macchioni, E. Clot, O Eisenstein, R. H. Crabtree, J. Am. Chem. Soc. 2005, 127, 16299; c) G. Song, X. Wang, Y. Li, X. Li, Organometallics 2008, 27, 1187; similar observations have been made with osmium and precursors and in certain palladation reactions: d) M. Baya, B. Eguillor, M. A. Esteruelas, M Loivan, E. Onate, Organometallics 2007, 26 6556; e) H. Lebel, M. K. Janes, A. B. Charette, S. P. Nolan, J. Am. Chem. Soc. 2004, 126, 5046.

[15] a) M. Albrecht, Chem. Commun. 2008, 3601; b) O. Schuster, L. Yang, H. G. Raubenheimer, M. Albrecht, Chem. Rev. 2009, 109, in press.

[16] Depending on the substituents at the nitrogen atoms and the location of annelated rings, the position of the metal-bound carbon may formally deviate from $\mathrm{C}(4)$. For example, in complex 10, the metal-bound carbon is formally $\mathrm{C}(5)$. For reasons of consistency, the atom labeling of Scheme 1 is preserved throughout the entire article and the metal-bound carbon is referred to as $\mathrm{C}(4)$ carbon

[17] For other strategies, see ref. [14] and : a) X. Hu, I. Castro-Rodriguez, K. Meyer, Organometallics 2003, 22, 3016; b) A. A. Danopoulos, N. Tsoureas, J. A. Wright, M. E.
Light, Organometallics 2004, 23, 166; c) N. Stylianides, A. A. Danopoulos, N. Tsoureas, J. Organomet. Chem. 2005, 690, 5948; d) C. E. Ellul, M. F. Mahon, O. Saker, M. K. Whittlesey, Angew. Chem., Int. Ed. 2007, 46, 6343.

[18] E. Kluser, A. Neels, M. Albrecht, Chem. Commun. 2006, 4495.

[19] M. Iglesias, M. Albrecht, unpublished results.

[20] a) A. R. Chianese, B. M. Zeglis, R. H. Crabtree, Chem. Commun. 2004, 2176; b) M. Viciano, M. Feliz, R. Corberan, J. A. Mata, E. Clot, E. Peris, Organometallics 2007, 26, 5304.

[21] a) A. R. Chianese, A. Kovacevic, B. M. Zeglis, J. W. Faller, R. H. Crabtree, Organometallics 2004, 23, 2461 b) M. Alcarazo, S. J. Roseblade, A. R. Cowley, R. Fernandez, J. M. Brown, J. M. Lassaletta, J. Am. Chem. Soc. 2005, 127, 3290; c) G. Song, Y. Zhang, X. Li, Organometallics 2008, 27, 1936

[22] a) M. Albrecht, R. H. Crabtree, J. Mata, E. Peris, Chem. Commun. 2002, 32; b) M. Albrecht, J. R. Miecznikowski, A. Samuel, J. W. Faller, R. H. Crabtree, Organometallics 2002, 21, 3596; c) M. Heckenroth, A. Neels, H. Stoeckli-Evans, M. Albrecht, Inorg. Chim. Acta 2006, 359 1929

[23] M. Heckenroth, E. Kluser, A. Neels, M. Albrecht, Angew. Chem., Int. Ed. 2007, 46, 6293.

[24] M. Heckenroth, A. Neels, M. Albrecht, Dalton Trans. 2008, 6242

[25] M. Heckenroth, A. Neels, M. G. Garnier, P. Aebi, A. Ehlers, M. Albrecht, submitted.

[26] a) K. J. Cavell, D. S. McGuinness, Coord. Chem. Rev. 2004, 248, 671; b) D. C. Graham, K. J. Cavell, B. F. Yates, Dalton Trans. 2006, 1768 ; c) A. M. Magill, B. F. Yates, K. J. Cavell, B. W. Skelton, A. H. White, Dalton Trans. 2007, 3398.

[27] For other exceptionally strong donor ligands, see: a) K. Denk, P. Sirsch, W. A. Herrmann, J. Organomet. Chem. 2002, 649, 219; b) $\mathrm{P}$ Bazinet, G. P. A. Yap, D. S. Richeson, J. Am. Chem. Soc. 2003, 125, 13314; c) M. Mayr, K. Wurst, K.-H. Ongania, M. R. Buchmeiser, Chem. Eur. J. 2004, 10, 1256.

[28] L. Yang, A. Krüger, A. Neels, M. Albrecht, Organometallics 2008, 27, 3161.

[29] A. Krüger, A. Neels, M. Albrecht, unpublished results.

[30] V. Lavallo, C. A. Dyker, B. Donnadieu, G. Bertrand, Angew. Chem., Int. Ed. 2009, 48, in press.

[31] P. Mathew, A. Neels, M. Albrecht, J. Am. Chem. Soc. 2008, 130, 13534.

[32] A. Poulain, A. Neels, M. Albrecht, unpublished results.

[33] a) A. R. Chianese, X. Li, M. C. Janzen, J. W. Faller, R. H. Crabtree, Organometallics 2003 22,1663 ; b) R. A. Kelly, H. Clavier, S. Giudice, N. M. Scott, E. D. Stevens, J. Bordner, I Samardjiev, C. D. Hoff, L. Cavallo, S. P. Nolan, Organometallics 2008, 27, 202.

[34] D. J. Lavorato, J. K. Terlouw, T. K. Dargel, W. Koch, G. A. McGibbon, H. Schwarz, J. Am. Chem. Soc. 1996, 118, 11898.

[35] H. G. Raubenheimer, S. J. Cronje, Dalton Trans. 2008, 1265.

[36] A. Poulain, A. Neels, M. Albrecht, Eur. J. Inorg. Chem. 2009, in press. 